HRJ

v.2 n.9 (2021)

Recebido: $19 / 11 / 2020$

Aceito: $22 / 12 / 2020$

\title{
A novidade mora ao lado: a literatura de cordel como material educativo para trabalhadores da Atenção Primária de Saúde de Ceilândia-DF
}

\author{
Daniela Sousa de Oliveira ${ }^{1}$ \\ Silvana Pereira Dantas Evangelista de Souza ${ }^{2}$ \\ Caroline Jonas Rezaghi Ricomini Nunes ${ }^{3}$
}

1. Terapeuta Ocupacional. Residente do Programa de Residência Multiprofissional em Saúde Mental do Adulto, Escola Superior de Ciências da Saúde - ESCS/FEPECS, Distrito Federal. Mestranda do Programa de Pós-Graduação em Saúde Coletiva, Universidade de Brasília - UnB. E-mail: aleinda21@gmail.com.

2. Fisioterapeuta Especialista em Saúde Coletiva. Pós-Graduada em Fisioterapia Dermatofuncional. Residente do Programa de Residência Multiprofissional em Saúde Mental Infantojuvenil- ESCS/FEPECS. E-mail: silvana.dantas2705@gmail.com.

3. Terapeuta Ocupacional. Especialista em Saúde Coletiva, Fundação Oswaldo Cruz - Fiocruz. Mestre em Ciências da Saúde pela Universidade de Brasília - UnB. E-mail: carolinejonasnunes@gmail.com.

RESUMO: Trata-se de um estudo de abordagem qualitativa desenvolvido com trabalhadores da Atenção Primária de Saúde (APS), no momento de conversão do modelo biomédico/tradicional para o modelo de base comunitária (Estratégias de Saúde da Família - ESF). Realizou-se rodas de conversas para sensibilização dos trabalhadores que tinham o processo de trabalho pautado no modelo biomédico, com o objetivo de introdução da concepção da ESF. A metodologia utilizada para produção das informações foi entrevista semiestruturadas e gravação por um gravador de voz dos encontros, analisada pela técnica teórica-reflexiva. Utilizou-se como material educativo o cordel, um recurso que além de facilitar o desenvolvimento da temática ainda proporcionou aos participantes e facilitadores um espaço para a dialética. A utilização da literatura do Cordel como material educativo possibilitou maior envolvimento dos participantes com as temáticas trabalhadas, construção de vínculos, identificação com as problemáticas apresentadas e principalmente produção de afeto entres os implicados. 
PALAVRAS-CHAVES: Atenção Primária de Saúde. Estratégia de Saúde da Família. Modelos de saúde. Educação em saúde. Cordel.

\section{The novelty lives next door: cordel literature as educational material for workers in Primary Health Care in Ceilândia-DF}

ABSTRACT: This is a qualitative approach study developed with Primary Health Care (PHC) workers, at the time of converting the health care model, converting the biomedical and traditional model to the community based model, to Health Strategies of the Family (FHS). The objective was to hold talks to raise awareness among workers who had the work process based on the biomedical model, to introduce the concept of the FHS. The methodology used for the production of the information was semi-structured interviews and recorded by a voice recorder of the meetings, analyzed by the reflective theoretical technique. The use of cordel as educational material was a resource that, in addition to facilitating thematic development, also provided participants and facilitators with a space for dialectics.

KEYWORDS: Primary Health Care. Family Health Strategy. health model. Health education.

\section{INTRODUÇÃO}

O Sistema Único de Saúde (SUS) mesmo com o reconhecimento da saúde como direito de todos e dever do Estado ainda assim possui inúmeros desafios para a implementação de um sistema de saúde universal, equânime e integral ${ }^{1}$. Durante os últimos anos, é notável como a Atenção Primária de Saúde (APS) tem sido aprimorada e colocada como nível de atenção mais importante do sistema, para tal, diversas tecnologias têm sido desenvolvidas para ampliar o escopo das ações da APS com intuito de torná-las mais efetivas e resolutivas. A Política de Atenção Básica (PNAB) traz consigo elementos importantes para a construção da APS no Brasil, com um olhar plural da realidade dos milhares de brasileiros. Ser o primeiro contato dos usuários com o sistema de saúde e a 
organização da rede, faz da APS um nível de assistência fundamental para o funcionamento do sistema de forma integral, equânime e universal. É a partir desse primeiro contato que o usuário percorre os demais níveis de atenção e é acompanhado em sua totalidade por longo tempo, o que caracteriza a longitudinalidade do cuidado. Além de se responsabilizar pela saúde dos indivíduos, a APS propõe-se a olhar para o território, entendendo que este oferece tanto riscos quanto agentes promotores de saúde, e considera a cultura, os hábitos e as vulnerabilidades sociais como campos da saúde. A partir do modelo ESF, a família configurou-se como elemento central na organização do serviço e nas ações de promoção,

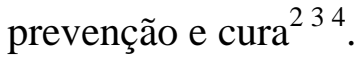

Ainda assim, a APS, enquanto comprometida com acesso, resolubilidade e custoefetividade, tem-se desdobrado para alcançar e produzir cuidados de qualidade, que com financiamento adequado é capaz de produzir saúde de qualidade. Tem a responsabilidade na organização e coordenação dos fluxos de procura por cuidados em saúde, por usuários, além de possibilitar atendimento direcionado as necessidades da comunidade. Que sob comando da Estratégias de Saúde da Família (ESF) tem mostrado notória desenvoltura nas ações e serviços de saúde que vislumbrem a eficácia e eficiência nos atos de promoção da saúde e prevenção de agravos ${ }^{5}$.

A ESF tem sido um modelo de atenção à saúde com a proposta de reorganização não apenas da assistência do SUS, mas possibilitar o aumento da participação dos profissionais, gestores e usuários nos processos de trabalho e cuidado em saúde (BRASIL, 2010) ${ }^{6}$. Promove-se saúde tendo o usuário como corresponsável e ator principal, firmandose na atenção integral, equânime e contínua que muito tem a fortalecer o SUS. Nesse modelo não há distanciamento entre os profissionais e usuários, isso facilita para construção de vínculos e adesão às propostas interventivas. Afirma-se que a ESF tem capacitação de resolver $80 \%$ das demandas, com isso, diminuiria a procura assistencial de 
hospitais e ambulatório, visto que a maioria dos que procuram são pessoas com doenças crônicas agudizadas ${ }^{8}$.

Macinko (2018) ${ }^{9}$ evidenciou que os territórios onde operam a ESF tem maior cobertura e acesso aos serviços pelos usuários; redução da mortalidade infantil e adulto, ampliação da carteira de serviços, como odontológicos; redução de hospitalizações de casos sensíveis à APS; sinergias entre os programas sociais, como bolsa família; maior infraestrutura e também produção de pesquisa para avaliação e monitoramentos de indicadores ${ }^{9}$. Apesar dos obstáculos, a ESF tem-se consolidado como modelo de atenção à saúde que proporciona acesso universal e concretização do direito à saúde. Porém, devido à supremacia do modelo tradicional biomédico, no qual, de um lado, se observa a doença e são promovidas soluções curativas focadas na atuação profissional do médico e, de outro lado, foca-se no trabalho multiprofissional e interdisciplinar, clínica ampliada. Nesse modelo o objeto de cuidado são as pessoas e seus determinantes e condicionantes de saúde, tendo em vista seu contexto ${ }^{1}$.

O Distrito Federal por muito tempo sobreviveu aos entraves de um sistema fragmentado e pouco resolutivo com coexistência dos dois modelos: tradicional biomédico e ESF. Muitas foram as mudanças e programas implantados, no entanto, sempre focado no modelo tradicional biomédico. Em 2016, com perspectivas de mudança do modelo, o qual ainda orientado pela PNAB 2012, o Ministério da Saúde (MS) estimulou a implantação do modelo de Estratégias de Saúde da Família em todas as UBS. Nesse contexto, foi lançado o Projeto Brasília Saudável, com a intenção de transformar as UBS que funcionassem no modelo tradicional em ESF, visto que o primeiro modelo apresenta baixa resolubilidade, ineficiência na longitudinalidade, na integralidade do cuidado e desarticulação com a rede de atenção à saúde ${ }^{10}$. 
Nesse contexto de transição de modelo, houve o processo de conversão das equipes da APS, conhecido como ConvertDF, o qual se dividiu em quatro fases: preparatória, momento de analisar os serviços com demandas por entendimentos da população; elaboração e preparação, discussões com o conselho de saúde e apresentação do projeto a alta gestão do GDF; normatização e divulgação, elaboração das portarias SES-DF n ${ }^{\circ} 77$ e 78 de 14 de fevereiro de 2017 e realização de reuniões nas regiões de saúde do DF; planejamento territorializado, aprovação do plano de conversão e composição das equipes em transição; para dessa forma se chegar à implantação, na qual ocorreram as capacitações teórico e prática, mudanças de especialidades de atuação na SES-DF e regulamentação da operacionalização do NASF-AB ${ }^{11}$. Esse processo de conversão também ficou conhecido como restauração da APS no Distrito Federal. Aos trabalhadores foram colocadas as alternativas de ficar na APS e vivenciar a conversão ou serem transferidos para outro nível de atenção. Dentro do processo mudança de modelo, Portaria SES-DF no 77 de 14 de fevereiro de 2017 cria a política de Atenção Primária de Saúde do DF respaldada nos atributos e diretrizes da ESF, pela Lei Distrital $n^{\circ}$ 6133, de 6 de abril de 2018, a qual certifica a ESF como modelo de APS do $\mathrm{DF}^{10}$.

Em 2017, o DF contabilizava 277 ESF com cobertura da APS de 34\%; em 2018, com implantação da conversão, passou a ter 549 ESF com cobertura de $69,1 \%$; a população atendida pela ESF passou de 1.038 .750 para 2.058 .750 , em que cada equipe de saúde se responsabilizou por um território de 3.750 pessoas. A proposta inicial foi de alcançar toda a população do DF, no entanto, tendo em vista a equidade, as Regiões Administrativas com maior vulnerabilidade foram priorizadas. Como forma de fortalecer ainda a estratégias de implantação da ESF, foram realizados concurso públicos para provimento de contratação de médicos de família e comunidade ${ }^{10}$. 
A conversão do modelo de atenção à saúde no DF foi movida pela reorganização total e estruturação dos níveis de atenção. A Portaria SES-DF nº 78 de 14 de fevereiro de 2017 estabeleceu a constituição de equipes em transição mediante condicionado à capacitação e cumprimento dos quesitos para integrar as equipes ${ }^{10}$. As capacitações eram voltadas para médicos, técnicos de enfermagem e enfermeiros. Os médicos e enfermeiros que alcançassem desempenho satisfatório poderiam mudar sua especialidade para "Família e Comunidade". Ao todo foram formados 110 médicos para equipes. A adesão dos profissionais nas equipes de transição foi bastante significativa, o que permitiu ampliação da cobertura ${ }^{10}$.

Nesse processo de capacitação das equipes em transição residentes do Programa Multiprofissional de Saúde da Família teve a oportunidade de trabalhar com duas UBS de Ceilândia-DF, que precisam de intensificação nos processos educativos relacionado a inserção do modelo de ESF. E como proposta de ensino em serviços foi apresentado um projeto com finalidade de construir rodas de conversas, horizontalizadas para promoção de espaços coletivos democráticos e trocas de saberes, com base no método da roda de conversas com a finalidade de produzir conhecimento e educação, proposto por Campos $(2000)^{12}$. Com a perspectiva de contribuir reflexões críticas e transição das práticas, foram criadas histórias no formato de literatura de cordel para exemplificar a estrutura do trabalho na ESF de forma mais criativa, participativa e acolhedora. A literatura de cordel são ilustrações impressas em xilogravuras, que durante muito tempo tinham como público-alvo pessoas semianalfabetas e alfabetizadas. Teve grande relevância na cultura brasileira, em virtude do baixo preço e pelo teor humorístico e regional da vida cotidiana ${ }^{13}$.

A literatura de cordel apresenta-se como uma estratégia interessante de comunicação, sobretudo, porque suas rimas e versos atraem a atenção das pessoas ao repassar informações de saúde de forma lúdica, configurando-se como poderoso 
instrumento para ações educativas ${ }^{14}$. A intenção de utilização do recurso justifica-se porque na literatura de cordel a preocupação não está em narrativas de fantasia, mas carrega uma temática que retrata a realidade, dentro de um contexto leve e ao mesmo tempo reflexivo. É um instrumento de muito potencial que incentiva a criatividade e a espontaneidade com foco na oralidade de rimas fáceis de memorizar ${ }^{15}$.

Por fim, nota-se que a ESF é um modelo que possibilita a integração, valorização dos profissionais, além promover diminuição da sobrecarga de trabalho pelo trabalho colaborativo da equipe. Mudar a realidade de processo de trabalho tão engessado quanto dos profissionais que trabalharam por anos no modelo biomédico significa pensar em soluções graduadas e mutáveis.

\section{METODOLOGIA}

Trata-se de um estudo com abordagem qualitativa de caráter descritivo, com a perspectiva reflexiva-teórica. Que tem como base a experiência de Galheigo $(2020)^{16}$ que trabalhou em sua pesquisa, a problematização como uma proposta interventiva e metodológica para construções coletivas nos processos de levantamento de estratégias e soluções de problemas $^{16}$. O que corrobora substancial com a proposta desse estudo que se desdobra ao analisar a utilização da literatura de cordel como material educativo com trabalhadores da APS e, assim, descrever os acontecimentos e fenômenos ocorridos com interesse nos significados e principalmente nas experiências vividas ${ }^{16}$. O estudo reflexivo também é conhecido por proporcionar engajamento tanto do pesquisador quanto do participante orientados na produção de conhecimento, num processo de reflexividade em que se encontram as práticas da vida social ${ }^{17}$.

Os processos interventivos ocorreram em duas UBS da Região Administrativa de Ceilândia-DF, conduzidas por Residentes Multiprofissionais em Saúde da Família da 
Escola Superior da Ciências da Saúde - ESCS no ano de 2017 a 2018, das seguintes categorias profissionais: Terapeuta Ocupacional, Serviço Social e Fisioterapia. O públicoalvo foram trabalhadores da APS que estão nas equipes de transição do modelo biomédico para o modelo de ESF. Foram utilizadas oficinas de sensibilização, observação participante, diário de campo e entrevistas semiestruturadas. Este artigo se propõe a analisar os impactos no emprego de folhetos em xilogravura da literatura de cordel no processo de capacitação dos profissionais que passaram pelo período de transição do modelo biomédico para o modelo de ESF. Acredita-se que a literatura de cordel favorece, dentro do processo educação e aprendizagem, envolvimento e estreitamento das relações dentro de uma coletividade, por ser um recurso dinâmico e por retratar a vida cotidiana de forma poética ${ }^{15}$.

Foram realizados cinco encontros com duração aproximada de $2 \mathrm{~h} 30$ em duas UBS de Ceilândia-DF. Em cada unidade os participantes foram divididos em dois subgrupos, entre os turnos matutino e vespertino. Participaram 45 profissionais de diferentes categorias profissionais, como: médicos, enfermeiros, agentes comunitários de saúde, técnico em enfermagem, profissionais do administrativo, porteiros e serviços gerais. Houve três desistências.

O percurso metodológico deu-se em três etapas: a primeira, que ocorreu antes da realização dos encontros educativos, foi aplicação de entrevistas semiestruturadas com objetivo de coletar informações sobre as potenciais lacunas com profissionais de cada UBS. Os temas centrais identificados pelas entrevistas foram: APS, diferenças entre os modelos ESF e biomédico, rede de atenção à saúde, princípios e diretrizes do SUS, o trabalho humanizado, linhas de cuidado e fluxogramas descritores, trabalho em equipe, princípios e diretrizes da APS, autonomia, empatia, ética profissional, tecnologias leves, territorialização, cadastramento, controle social, Núcleo Ampliado de Saúde da Família e Atenção Básica e clínica ampliada. Segunda: ocorreu a tabulação das informações 
coletadas pela entrevista semiestrutura para embasar a criação e incorporação dos temas no molde de folhetos cordel. A terceira foi a realização dos encontros tendo como foco as histórias em xilogravuras, dentro de uma proposta de roda de conversa.

Ao todo foram confeccionadas dezessete história no formato da literatura de cordel, sendo sete criadas a partir das questões e reflexões desenvolvidas pelo coletivo. As histórias tratam sobre APS e o modelo de ESF como substituto ao modelo biomédico. Este estudo foi aprovado no Comitê de Ética em Pesquisa da Fundação de Ensino e Pesquisa em Ciências da Saúde - FEPCS, em acordo a Resolução de 196, do Conselho Nacional de Saúde, CAAE: 73150017.6.0000.5553.

\section{RESULTADOS E DISCUSSÕES}

Para Campos (2000) ${ }^{11}$ o método de roda de conversa é um espaço que tem proposição de construir ensino e aprendizagem, um lugar onde é permeado pela democracia reconhecendo as vivências e os saberes em suas horizontalidades. Coloca como protagonista o conhecimento reflexivo, perpassando por implicações de afeto, de autonomia e de criatividade. Nesse sentido a roda é um dispositivo que oportuniza construção de educação em saúde com o objetivo de fortalecer ainda mais o protagonismo dos trabalhadores, além de instrumentalizá-los para enfrentamentos cotidiano e principalmente conectar e estreitar as relações nos processos de trabalhos ${ }^{12}$.

A implementação da ESF enquanto modelo prioritário no DF constitui-se em um processo de reformulação constante que deve perdurar por muitos anos, uma vez que atualmente o modelo de ESF é o que mais se aproxima dos princípios e diretrizes do SUS. Vale ressaltar que para efetivar as mudanças é necessário envolvimento de todos os atores, desde a concepção, o campo das ideias, até tomada de decisões, ou seja, há a cogestão. Dentro de um processo cooperativo, a cogestão coloca-se como metodologia de trabalho 
que visa "redistribuir os poderes nas relações sociais afirmando como estratégias democráticas a transformação dos serviços" ${ }^{18}$.

A construção coletiva do conhecimento reflexivo aponta para "agir na contramão das forças hegemônicas", com a possibilidade de indução de "novos fluxos de poder e valores" dentro dos serviços de saúde nos quais são empregados a ESF. Campos $(2000)^{12}$ enfatiza que o método da roda é essencial para as instituições de saúde, pois além de criar um ambiente de trabalho focado no desempenho horizontal da equipe também é um espaço riquíssimo de capacitação das pessoas. A proposta de capacitação e utilização da literatura de cordel deu-se com intuito de poder criar um espaço de fala e que amenizassem os efeitos contrários da conversão do modelo, como por exemplo a resistência, e retratar de forma criativa e participativa o cotidiano das equipes. Nesse sentido foram incorporadas sugestões temáticas pelos participantes, o que foi fundamento tanto para formação de vínculos com os facilitadores quando para criar um ambiente seguro de confiança ${ }^{18}$.

As histórias delineadas no formato de cordéis foram elaboradas pelos Residentes de Saúde da Família, as quais se desenrolam em torno da chegada de família fictícia em região de vulnerabilidade social e econômica e onde passa a ser atendida por uma equipe ESF, nomeada de "paineira", com enredo principal que norteou os cordéis. No decorrer da trama vão sendo trabalhados conceitos, atributos, processos organizativos, tecnologias e dispositivos da APS de forma dinâmica e descontraída na oportunidade de possibilitar reflexões de identificação com as circunstâncias apresentadas, problematização e a criação de estratégias. Seguem abaixo os quadros os quais trazem os cordéis discutidos criados exclusivamente para desenvolvimento das cincos rodas de conversas sobre a conversão do modelo biomédico para o modelo de ESF.

\section{Quadro 1 - Cordéis da primeira roda de conversa}


Menina, se avexe não que uma história eu vou contar. A história de um grande amô. Pra ocê se apaixoná.

Numa cidade distante, existia um retirante, que tinha uma ideia fixa: de morar em cidade grande.

Um amigo rico do moço, foi quem pagou a passagem. Joaquim, sorriso no rosto, começou sua viagi.

Chegando na capital, se instalou numa pousada. Com cuidado no dinheiro, pra num entrar numa furada.

Tinha almoço, tinha janta, só num tinha o cafezinho.

Qual surpresa ele não teve, ao ver uma linda moça.

Perguntou o nome dela. Mas ela tinha que ir lavá louça.

Não saía da cabeça, a imagem da menina.

Formosura, tão singela, seria a sua sina.

Noutro dia ele voltou, no mercadinho, ali perto.

Ansiando na menina.

Desse um beijo muito certo. Ficou sabendo do nome da menina era Filó. Ela faltou o serviço, porque tava com a avó.

Joaquim desesperado, pra conversar com a menina, tratou logo de comprar, uma bonita bonina.

Filomena ao receber aquela bonita bonina. Por Joaquim se encantou, amor lindo de menina.

Joaquim bem apressado, pensando nos finalmente. Pediu a Filó pra Vó, mas aí, caiu seu dente.

Passado o aperreio, Joaquim se desculpou. A vó falou bem assim: - A minha neta eu te dou.

Joaquim ouviu falar, por ali, tinha um postinho. Se avexou foi pra cuidar, do bendito do dentinho.

Avistou um rapazote, com um jeito muito sagaz, e perguntou: - Meu rapaz, aqui encontro um dentista?

Que sorte a de Joaquim a agenda estava aberta. $\mathrm{O}$ dentista cuidou do dente e ele saiu bem contente.

Aproveitando a "viagi", Joaquim avistou um médico.

\section{O casamento por Silvana Souza}

Falou de casamento, e tava amedrontado...

O médico perguntou: - Oxe, bichim, que se passa?

Joaquim encabulado, perguntou de camisinha...pois já tinha engravidado, moça de pílula de farinha.

O doutô experiente explicou tudo calmamente. Joaquim agora consciente, sabe se prevenir. Nem doença, nem menino, aprendeu essa lição. Agora pode curtir sua flor, aquele seu mulherão.

Chegou o grande dia. O esperado do casório. Mas cadê o Joaquim? Ele tava no cartório. Só demorou um pouquim. E a noiva tava aflita. Rezou logo o Crein Deus Pai, Ave Maria trei bendita.

Joaquim pegou o padre, puxou ele na batina. Ô ômi me case logo. Que hoje eu vô pra serpentina.

E assim se asucedeu o casório de Joaquim e Filó. E então ficou sozinha, a bichinha da avó.

\section{Teobaldo e Sua Equipe por Silvana Souza}

Porventura, encontrei-me com Joaquim, que fala: - Quando entrei aqui no posto, conheci o Teobaldo, um cabra desenrolado, que me chamou logo pro lado. - Quinzinho, ocê fez certo, em vir cuidar da saúde, pra num ter nenhum problema. É a melhor atitude.

Saiba aqui, eu num tô só. Comigo, aqui, tem mais gente, Têm médico, dentista, ACS. Sem contar a enfermagem.
Teobaldo é enfermeiro da família, sim sinhô. Quem conversar com ele, vai sentir o seu amor.

Paciente, prestativo, atento às necessidades, gripe, febre, dor de barriga. Qualquer eventualidade.

Depois de assuntar com Teobaldo, Joaquim diz:
- Agora, preste atenção, um conselho eu vou te dar. Cuide da sua saúde, e evite se preocupar..

Muita coisa eu aprendi e a melhor eu vou falar: Cada um tem uma função, eu sô atô principár!

Vou espalhar por aí, como é bom se prevenir. Doente não quero ficar, e na UTI terminar. 
Vou contar com essa equipe, sempre que eu precisar. Desse serviço, só tenho coisa boa pra falar.

Minha casa tá inserida numa área de abrangência. Pra melhor organizar a forma de assistência.
As portas da unidade, encontram-se sempre abertas. Então, comunidade, peço então tenha paciência.

E quando lá não dispõe, daquilo que ocê precisa. Eles tratam de fazê logo o encaminhamento.
Mas que danado que é isso? É encaminhamento responsável. Sem cuidado não ficamos, isso eu posso garantir. $\mathrm{O}$ que a rede oferece, podemos usufruir.

Para além de um modelo que tem o poder organizativo, a ESF tem como objetivo os cuidados centrais nas famílias e todos os desdobramentos que a circunda. Sendo importante conhecer as dinâmicas e suas necessidades singulares e coletivas, pois a família é o primeiro espaço de identificação e explicação dos adoecimentos e soluções, passando a ser a primeira unidade de cuidados a ser entendida pelos profissionais da saúde. Esse reconhecimento concebe o cuidado compartilhado em que os integrantes familiares passam a ser protagonistas de sua própria história se constituindo em verdadeiros promotores da saúde. Por esses motivos, as primeiras histórias de cordel vieram com o enfoque de trazer a família como foco de transferência e validação das estratégias de promoção, prevenção e reabilitação em saúde. Não como espectadoras, mas como pessoas ativas inventoras de saúde ${ }^{19}$.

Após análise das entrevistas semiestruturadas, percebeu-se que a maior parte dos entrevistados tiveram dificuldades quanto: à composição e competências individuais e coletivas dos profissionais inseridos no modelo de ESF, como também aspectos relacionados aos conceitos da humanização. Os próximos cordéis objetivaram trazer provocações quanto à organização do modelo e tecnologias de trabalho, explicitando o trabalho em equipe e inseparabilidade com os gestores.

\section{Quadro 2 - Cordéis da segunda roda de conversa}


Bem-vindo minha gente, sou Afonso, diretor da atenção primária. E vim lhes contar Que aqui é diferente da secundária.

A ESF vai expandir a nossa atenção.

Favorecer organização, do trabalho humanizado como primeira condição.

Ampliar a resolutividade, pois o que ofertamos aqui, não é caridade. Uma vez que conheceremos a verdadeira realidade.

Aprofundar nos princípios e diretrizes. Não esquecendo das cicatrizes, pois o que pretendemos, meu amigo, é você junto comigo.

Melhorar as condições de saúde. Das pessoas, da comunidade. Todos, de qualquer idade. Além de otimizar com a gestão. Não vim aqui passar o bastão.

Pois estamos juntos por uma única razão.

Custo-efetividade com alteridade. Dando espaço para reciprocidade. Atenção à saúde de base comunitária, porque assim que ela se torna igualitária.

A ideia de que os cuidados da primária são simples, deixou de ser realidade. Uma vez que trabalharemos com às necessidades. Autonomia, determinantes $\mathrm{e}$ condicionantes de saúde, pois assim que Mendes alude.

A ESF não é uma sigla. Nem mudança de paradigma. Está aqui para não se tornar um enigma.

Como você pode observar, na ESF é preciso escutar às dificuldades e a elas monitorar.

Corresponsabilização é nova onda de ação. Ofertamos aos outros pontos de atenção uma rede de referenciação.

Garantir a integridade não se trata de uma homenagem. Centramos na pessoa, já que a doença não ressoa.

Um trabalho realizado em equipe, trocando saberes a partir do cotidiano, posto que não estamos no best-seller hollywoodiano.

Meu sinhô, me responde uma coisa? - Sim, Teobaldo. Diz, seu diretor. Trabalhar de forma compartilhada não vai aumentar a caminhada?

- Não, caríssimo!

Trabalhar de forma compartilhada, irá fortalecer nossa caminhada.
- Um trabalho colaborativo devemos implementar para a população poder acessar.

Usuários, gestores, profissionais. Vamos juntos tirar o povo dos hospitais.

- Participar do processo de territorialização, visando à organização. Realizando busca ativa e notificação. Para assim identificarmos a complicação.

- Cadastramento é evento que todos devem estar por dentro.

Área adstrita é colocar o pé no terreiro, como, Carlos Chagas, o aventureiro.

- Ações educativas que interfiram não só no processo de saúde-doença. Se aconchegando com toda licença, pois o intuito aqui, hoje, é fazer a diferença.

\section{Primeiro contato por Daniela Oliveira}

Humanização é para gestores, usuários e profissionais. Envolvendo-se de questões situacionais. Sua criação teve relevância para estreitar a distância, a fim de garantir a singularidade em todas as circunstâncias.

Inseparabilidade entre a atenção e gestão.
Não é uma sugestão, é a razão.

Transversalidade e autonomia, pois é um protagonismo que alivia.

A construção é coletiva e com uma perspectiva, de alcançar o cidadão, pra com ele fazer a humanização.
Gastão já dizia, em saúde, a humanização volta-se para compromisso, sem muito aviso.

De tal modo que o usuário veja o seu prontuário. E nessa sintonia que almejamos a garantia. Pois considera o humano em sua capacidade criadora 
não sendo uma mera, espectadora.

Compromete-se com uma nova relação. E com o aumento do grau de comunicação. É um por todos e todos por um. Como os três mosqueteiros que já pensaram em humanizar e o povo agradar.

Diz Teobaldo

na reunião da equipe: -

"Paineira", onde estavam todos presentes. E ninguém achou aquilo besteira.

Roberto, ACS: - Minha gente, vale lembrar da cogestão onde não tem patrão.
O SUS faz universalidade, integralidade, equidade, mas a humanização está no campo da subjetivação.

É mesmo, Roberto, diz dôtor Sebastião. - Ela tem um envolvimento de empatia que não é o mesmo que a telepatia.

- É quando nos colocamos disponíveis, para ouvir e para não sermos passíveis.

Acrescenta, Marinalva:

-Saúde é uma experiência vivenciada pela pessoa e naquilo que ela conhece, pois, a saúde-doença é um movimento lhe padece.
Teobaldo, fecha dizendo

- Humanização é tipo uma revalorização. Minha, sua e para população.

O processo de mudança irá chegar em todas as instâncias. Os sujeitos serão afetados e novos territórios serão acalentados.

Neste sentido é preciso aceitar, a tarefa de reinventar.

Que humanidade não tempo e nem vaidade. É olho no olho. Coração com coração, para que haja a construção.

Fonte: elaborado pelas autoras.

Logo de início da formulação do projeto de intervenção, o tema de humanização foi encomendado pela gestão com a justificativa de que se os profissionais não soubessem seu significado, tal fato poderia ser entrave na construção de vínculo com os usuários. No entanto, como explicitado nos cordéis, é um processo que movimenta todos os atores (gestores, profissionais e usuário). Trabalhar a humanização nos diversos campos de competências profissional é de extrema relevância para o emprego de ações humanizadoras, uma vez que esse atributo não deve ocorrer de forma unidirecional, profissional-usuários, mas, multifatorial, gestores-profissionais-usuários-gestores-profissionais, ações que se movimento a partir das dinâmicas que se estabelecem entre os atores ${ }^{19} 20$.

Saber distinguir o modelo médico-centrado, biomédico, do modelo de base comunitária, ESF, tornou-se, durante a realização das rodas, fundamental para processo de conversão $^{19}$. A organização do trabalho do modelo biomédico, tradicional, é feito de forma fragmentada e verticalizada enquanto de ESF compartilhada e articulada nas trocas de 
saberes. Isso porque o trabalho em equipe é uma estratégia para enfrentar de forma conjunta as problemáticas que surgem nos territórios, divido assim a carga do trabalho ${ }^{20}$.

\section{Quadro 3 - Cordéis da terceira roda de conversa}

\section{A acolhida por Daniela Oliveira}

Sebastião, seu doutô, chegou cedo no posto muito disposto.

- Mariiiia, se achegue, mulher, vamos ver a temperatura e pressão, pra Sebastião te chamar na sessão.

- Ginivalllldo, diz

Marinalva,

- Como vai ômi! A diabetes tá atacada heim? Precisa ficar mais zen.

Teobaldo chega, - Diiiia!.

- Dia", diz Marinalva.

- Nalva, hoje vamos

começar

aplicar o acolhimento, que precisará de muito discernimento.

- Mas, Teobaldo, e o que estou fazendo aqui não é acolhimento, ômi?

- Não.

- E o que é, heim?".

- Triagem! Deixa de bobagem.
- Mulher de Deus, triagem é uma separação pra você fazer a escolha e seleção. Enquanto acolhimento é a humanização do serviço. Acolher é acolhida admitir, aceitar e escutar Pra aqueles que estão desprovidos.

É também dar atenção, agasalhar, receber; para as necessidades possamos compreender.

Acolhimento é um ato de aproximação, sem subestimação. É um estar perto de alguém.

Uma atitude de inclusão, que gera repercussão.

No seu trabalho e na melhora do usuário.

Escuta qualificada, construção de vínculo, garantia de acesso, pois a saúde está dentro de um macroprocesso.

Acolhimento é você trabalhar de forma a atender a todos. Que procuram os serviços de saúde, estabelecendo articulação com outros setores, pra que os preceptores tenham o encaminhamento responsável e o usuário não fique solitário.

$\mathrm{O}$ acolhimento acontece em todos os ambientes do posto. Não tem um local, mas uma postura ética global.

Não pressupõe hora do profissional, porque assim não é funcional.

Implica em compartilhamento de saberes que é nosso interesse. Angústias, invenções, estamos aí pra abrigar e agasalhar, em quaisquer situações.

- Nossa, Teobaldo! Diz Marinalva. - Não é que eu estava perdida.

- Não se preocupe, Mulher!

- Mas agora estou decidida a humanizar, para eu sintonizar.

E assim Teobaldo segue com Marinalva, fazendo ressalva sobre a acolhida.

Que é sua forma de trazer as pessoas para escolhidas!

\section{Ressignificando o território por Daniela Oliveira}

Territorialização em saúde traz consigo historicidade, pois isso é uma prioridade.

De adentrar com toda licença, meu senhor.
Considerando suas fronteiras, para não batermos de cara com as barreiras. Um território abraça relação, sem especulação.

Pois a realidade nos espera, de indivíduos de grupos, nós delimitando à atmosfera.

A territorialidade é o resultado de relações política, econômicas e 
culturais. Que assumem diferentes configurações estruturais.

Heterogeneidade espacial, pois, temos que ter $\mathrm{o}$ exercício de nos adaptar, já que o território se encontra permanente em movimento de construção, desconstrução e reconstrução, se preparando para o engajamento!
Ações epidemiológicas estão voltadas para prevenção, pois não deixamos à promoção.

Fazer a intervenção pra ambientes saudáveis, pra alimentação saudáveis, pra ambientes saudáveis, pra moradia, pra economia, pois, é assim que o SUS se amplia.
Território é ter responsabilidade e atuação compartilhada.

Meu amigo preste atenção para que você sintonize seu coração, com sensibilidade. Se apropriando de todas verdades e comece fazer a ação.

A reunião por Daniela Oliveira

- "Vamo umbora, gente, pra reunião!, diz Teobalto, sem muito intenção. - Que isso, seu narrador? diz Teobaldo. - Sentir falta de um pouco de amor.

- Como que tem? Sou visto como um ninguém. Tendo que fazer o trabalho de um alguém, que nunca esteve no meu lugar. Sabe, às vezes, penso em largar tudo de mão, pois sinto falta de comunhão.

- Me chama lá a paineira que vou-lhes aprontar um conteúdo de primeira.

- Você, narrador? diz

Teobaldo.

- Sim, ômi!

- Gente, seu narrador vai prestar uma lição. Que nós devemos prestar muita atenção.

Reunião de equipe é um momento onde os membros devem ter comprometimento. É quando podemos planejar pra trabalhar sem remediar.

Organização, avaliação.

Cabem a melhor das intenção. Pra um desenvolvimento
É imprescindível um movimento. Meu, seu, de todos, quiçá de nossos avós.

Aqui nós temos médico, enfermeiro, técnico, ACS, dentista, pois todos cabem na lista da interdisciplinaridade que precisa de assiduidade.

O importante é a troca, que invoca a complementaridade e que desmantela a vulnerabilidade.

O objetivo é garantir a qualidade da assistência ao usuário em qualquer eventualidade.

A construção é de todos. E todos nós são as construções. É assim que encontramos as soluções.

Reunião não é feita só de discussão. Mas na busca de interlocuções capazes de acionar e a todos a relacionar.

Planejamento de visitas, criação de grupos pra populações prioritárias. Porque assim que é a primária.

Trabalho do cotidiano, uma vez dizia Gastão, com método da roda que vem reflexão.
- Quer dizer então, que eu vou largar de atender à população? diz Sebastião.

- Vou ter que fechar a agenda, é? diz Teobaldo.

Calma, minha gente, melhor é cuidar da alimentação, do que do coração.

Quando estamos em reunião nos organizamos pra promoção e prevenção da vulnerabilidade é assim que faz a integralidade.

Um período sem agenda, pode significar dias sem contenda.

De crianças, de mães e de avós, pois desataremos os nós. Do trabalho morto, para trabalho vivo, como lembrou Merhy ao vivo.

Reunião gera participação e contribuições, de opiniões, habilidades e conhecimento. Não como um entretenimento. Mas valorizada e não se hostiliza.

Somos equipe e não grupo. Porque senão não me ocupo. Discussões de casos pra evitar o descaso. Revisão do processo de trabalho, registrado tudo em ata, para que sejamos democratas. 
Portanto, paineira, reunião se faz com amor no coração, pois é uma metodologia de estruturação da informação para as tomadas de decisão.
É face-a-face que emergem a especialidade. Num contraponto da multiplicidade.

Fonte: elaborado pelas autoras.

Umas das metodologias de trabalho mais importante e eficiência dentro na ESF é a reunião de equipe. Além de um espaço de atualização e organização da rotina, também é entendido como um momento de educação permanente e continuada, com perspectiva de produzir ações e serviços delimitados aos contextos dos territórios. Por meio de práticas compartilhadas destinas a atenção das pessoas e não aos procedimentos ou doenças, devendo ser um exercício no cotidiano das equipes ${ }^{21}$. A proposta de trabalhar a acolhida, território e reunião de equipe resgata dentro de imaginário de cada participante os processos de trabalho sobre as perspectivas do SUS, APS e ESF, pois em alguns momentos esses temas foram trazidos como barreira do próprio processo de trabalho ou até como exemplo de possíveis desarticulação da ESF que dividiam o mesmo espaço. Houve relatos antes da aplicação desses cordéis de que o acolhimento era responsabilidade dos técnicos em enfermagem e não de todos das equipes, de que as reuniões serviam apenas para aumentar a demanda de trabalho e de que a responsabilidade de ir ao território era apenas dos Agentes Comunitários de Saúde (ACS). Diante dessas afirmações equivocadas, foram trabalhadas reflexões que contestassem essas ideias ${ }^{21}$.

A reunião de equipe é momento de planejamento, organização, monitoramento e avaliação dos processos de trabalho. Um espaço aberto, democrático para expressão de opiniões, discussões de casos e elaboração de planos de ações. É pautado na ideia de interdisciplinaridade, em que os núcleos dos saberes se encontram na construção de soluções distintas para as mesmas problemáticas. O resultado dessas ações programadas pelas ESF aumenta exponencialmente o vínculo com as pessoas dos territórios como 
também a resolubilidade. A reunião de equipe torna-se substancial para o trabalho reflexivo e analítico da $\mathrm{ESF}^{23}$.

Quadro 4 - Cordéis da quarta roda de conversa

A Buchuda de Zé Neto por Silvana Souza e Daniela Oliveira

Maria Frô, esperta, vai ao posto de saúde acompanhar sua neta que dormiu com a porta aberta. Assim foi por toda noite.

Filó tava enjoada. Tadinha, não comeu nada. Tava bem aperriada. Nesse instante apareceu Teobaldo... falou assim:

- Minha fia, que traz ocê aqui?

- Dotô, tô assim tem dia! Mas, onti, só vomitava! Nem oji, eu num comi!

- Um inzame eu vou fazer em ocê, nina Filó. Mandei passear sua Vó. Vou fazer um teste rápido. Medo, ocê num há de ter. Esse teste é de bebê.

- Filomena, minha fia favor, aguarde então bem ali.

Enquanto ela esperava, o coração batia mais forte, pensou ir pro Rio Grande do Norte, queria tirar a sorte. Era só um devaneio.

Assim que acordou, chamou logo Joaquim: - Ô Quim, eu penso meu fii, penso, que aí vem meninim!.

Teobaldo, conta a realidade.

- O inzame deu positivo, Filó minha princesa, fique calma, o Joaquim será a sua fortaleza.
Contem com animação, Dona Fulô vai amar. A vozinha bem coruja, de novo, Fulô será.

Dona Fulô foi se achegano, passos largos, sem parar.

- Valei-me, Nossa Senhora, Buchuda, Filó está.

Joaquim se alegrou, foi muito com a avó. Não parava de chorar, a coitadinha de Filó.

Teobaldo assim falou:

- Não se esquece de vortar, nessa data mês que vem, queremos acompanhar tudinho do seu neném. Docês dois vamos cuidar. E o pré-natar começar. O melhor vamos fazer, tranquila pode ficar.

A notícia se espalhou, pra lá da região,

Joaquim quase morria, era tanta a emoção.

TOC! TOC!

- Filóóóóóóóóóóóóóóóóóo? Filomeááááááááááááá??"

— “Quem é? É Roberto, o ACS!".

- "Mulé de Deus, Bastião (o dotô da paineira) quer te vê, amanhã lá posto!

- Uai, ômi de Deus! Mas pra quê?
-Mulé, tu precisa começar logo teu pré-natar!

- Ixi, Berto! Num é que eu tinha isquecido!

-Bom tu me alembrar!

De volta ao posto de saúde, Filomena e Joaquim viram dotô Bastião, prosearam um pouquim, ele os deixou tranquilim.

Filó perguntou: - Ô seu dotô, me diz uma coisa... Esse inzame aqui, é pra quê mermo?

- É pra saber se os bichim do seu sangue, tão trabalhano direitim...

E este ôto aqui, é pra saber, se tu tem sífilis, hepatite $B$, rubéola, toxoplasmose ou HIV!.

- Vixe Maria! Ôs negócios de nome féi!

Crê in Dos Pai, seu dotô!

- Essa aqui ó, Filomena... É a caderneta da gestante! Tomi!

- E é seu dotô?!

- Sim, sinhora, diz Dotô

Bastião.

- Aqui tem coisas sobre seus direitos e deveres.

- Não vai me perder, hein?!? 
- Quê isso! Oxi! Vou perder não... cuidarei como de minha vida!

- Peraí um instantim!

Vou chamar aqui o

Teobaldo: Ô Teobaldoooo?

- Seu bichim, (vigilante) tu visse Teobaldo? Chama ele pra mim, tenha a bondade!

- Seu dotô, ele vem hoje não! Hoje é folga dele!

- Vixe Maria!!

Então, me chame Marinalva! (Marinalva era a técnica em enfermagem).

- Tu vai conhecer um baita duma metalinguagem! hahaha...

- Que isso seu dotô?”

- Se avexe não, bichinha!"

- Ela é que vai preencher a caderneta da gestante!

Menos mal! Pensou Filomena, aliviada por um instante!

De 26 semanas,
Acompanhada da avó, veio nossa Filomena,

Buchuda de dá dó.

Encontrou-se com Teobaldo:

- Valei-me Nossa Senhora do Bom Parto...

- Filó que barrigão é esse, menina?! São dois ou três hein? Hahahahaha...

- Vamo ver como tá a tua pressão...Humm...12x8...boa!

- Teu peso tá bom pra tua altura e pra tua idade gestacional!

- Mas e esse inchaço aqui, Filó?

— Tu tomou as vacinas?

-Tomei diretim, seu dotô!”.

- Tá de parabéns, visse?!

- Dona Fulô, ponha essa menina para caminhar, viu?

- Também dê a ela bastante água. Isso é falta de exercício e hidratação!

Lá se vão Dona Fulô e Filó, dobrando a esquina.
Pelas bandas da rua.... Dona Joaquina... uma véinha fuxiqueira fala:

- Fica esperta mulé, gravidez é coisa séria!

Filó, chega em casa pensativa: "Ainda bem que posso contar com enfermeiro, médico, ACS, técnica e dentista.... eles são pessoas de Deus mesmo! Sinto um cuidado tão grande pela minha saúde... todo lugar devia ser assim!

A primária é porta aberta é assim que tem que ser, mulher, homem, criança, a todos, indistintos, contemplar.

Filó e Dona Fulô aprenderam a lição: O postinho é bom pra todos, prevenção e promoção, também participação.

Deu Zica por Daniela Oliveira

Numa quinta-feira de tardizinha, veio ao mundo a pequenina menininha.. OpS! mENina, seu narrador? Diz seu Joaquim.

Pois bem,

Numa quinta-feira de tardizão

veio ao mundo um meninão

Debaixo de tanto

Buááá...Buááá..

Tchantchantantan!

Apareceu seu menino, uma formosura sem igual.

Parece com cara do avô

Que estava coberto de amor.
E o casal coloca o nome José Neto, pra se alembrar e trazer afeto. Ao seu José que não conhecerá seu neto.

Filomena diz:

-Mas, seu doutor, cadê meu menino, quero a ele amamentar.

Sem muito se falar, não fique com pressa sá menina a rotina ele precisa se cuidar.
- Muita calma nessa hora minha gente, o menino nasceu com cabecinha de dente, diz seu doutor.

- Minha nossa senhora Maria Fúlor.

Joaquim se assusta e dor de barriga ele acusa.

Filomena não presta atenção porque tamanho é o seu coração.

- Filommmena!

Filommmena! 
-Quem é? diz Joaquim.

- Sou eu, rapaz, Roberto, ACS!!!.

- Me diz aí, o menino nasceu?

- Nasceu! diz Joaquim...

- Como que foi, homem?

E Joaquim conta pro ACS o fato que se asucedeu.

Já na reunião de equipe, paineira, uma equipe ESF pioneira. Roberto veio assuntar:

- Minha gente estou com dor no coração. $\mathrm{O}$ menino de Filomena nasceu e merece muita atenção.

Microcefalia, o menino tem. Por causa daquele mosquito tosco, que merece está no calabouço.

Teobaldo, diz assim: - Vamos nos preparar pra auxiliar e melhor cuidar.

- Sebastião, seu doutor, uma visita temos que agendar, para saber das necessidades e no futuro a ele melhorar.

Marinalva, muito esperta, - A equipe do NASF precisamos chamar.

Lá tem terapeuta ocupacional, fisioterapeuta, serviço social, nutricionista, farmacêutico, psicólogo. que é melhor atendimento que podemos ofertar.

Margarida, a dentista, diz:

- Minha gente, primeiro vamos arrumar uma reunião com NASF e prosear, que

Teobaldo vai marcar.

A equipe muito informada estava, pois Sebastião foi ao menino visitar.

Paineira se reuni com o NASF para se apoiar. - O matriciamento começou, grita Teobaldo. Paineira que está pela metade, se completou com seu doutor Tebaldo começa a falar, explicando a situação do menino do capoeirão. Paineira, traz a questão.

O NASF muito engenhoso fica só na observação.

Nos finalmente da explanação a TO do NASF chama atenção.

- Pessoal, eu vou lhes contar que um PTS pro caso temos que arrumar.

Margarida, diz-Isso mesmo, vamo criar.

E por lá eles constroem um, que é de invejar.

- Filommmena!

Filommmena!

- É Roberto?. Grita Dona

Fulô.

- Nããããoooo!

Teobaldo, mulher!

- Dona Fulô queria lhe apresentar, essa aqui é a TO que vai nos auxiliar.

Também tem essa menina que é fisio e vai nos apoiar e ocês orientar.

- Se achegue minha gente, diz Dona Fulô, na cozinha Filomena estar.

De muito se prosear eles resolvem ampliar a atenção à saúde e outros equipamentos de saúde contactar.

\section{O NASF está na área por Daniela Oliveira}

Minha gente preste atenção pois o NASF tem uma intervenção, de apoio de ação. Que visa à interdisciplinarização.

Um trabalho intersetorial que não há igual educação permanente que é assim que a gente se entende.

Participação social, educação popular, promoção e humanização para alcançarmos à

descentralização.

O NASF tem o foco no território, experiências e troca de saberes

tem que ser notório.

PTS eu vou fazer como o suporte do NASF.

Porque assim vamos nos entender a trabalhar em conjunto, sem perder o rumo.

Não se avexe não.
Essa história ainda está em construção.

Pois uma lógica é construída de vivências, que é quando se têm as evidências.

Um aprendizado coletivo é o nosso objetivo, pois não nos cabe pensar em fragmentar.

Redes de atenção vamos juntos explorar para o nosso usuário poder enxergar alternativas e se corresponsabilizar. 
Sendo assim, é preciso que

o NASF assuma

responsabilidade de

cogestão.

Sob uma coordenação possibilitar uma construção. De fortalecimento da ESF, aumentando seu escopo de atuação.

Com o conhecimento técnico, o NASF não é nenhum mistério. Ele está vinculado a determinadas equipes e é um que não nos inibe.

Desenvolvimento de habilidades, pois queremos a equidade.

Está comprometido com a promoção, de mudança atitude, pois almejamos amplitude.
O NASF tem profissionais especialista. Todos com frente dá um suporte, pois tem vista um carimbo no passaporte. Da integralidade de cumplicidade.

Encaminhamento é coisa do passado. Para o NASF é discussão do caso. A equipe de referência tem em sua essência dividir e corresponsabilizar para com o NASF poder atuar.

Apoio matricial é uma metodologia que o NASF se apropria.

Equipe de referência tem um arranjo que busca eficiência.
O taylorismo acabou.

Gastão, o sanitarista, que divulgou.

Sem linha de produção, porque coloca o usuário na nossa mão.

Uma vez que o matricial gera transformação, que envolve todos os atores sem perder o foco em questão.

Técnico-pedagógico e assistencial, pois a dimensão de acesso do NASF

é exponencial.

Coordenação do cuidado é o que deve estar consolidado. No NASF na ESF, pois o intuito e se envolver para nos fortalecer.

Fonte: elaborado pelas autoras.

O Núcleo Apoio de Saúde da Família (NASF) teve sua nomenclatura redefinida para Núcleo Ampliado de Saúde da Família e Atenção Básica (NASF-AB). Não se constitui porta de entrada como a APS, mas presta suporte de retaguarda técnica, pedagógica e assistencial $^{22}$

O trabalho do NASF-AB somado aos da ESFs de forma integrada tem o poder de consequentemente aumentar o escopo de cobertura da APS, visando melhorias na prestação de cuidados. Durante a realização das rodas de conversas e como nas entrevistas semiestruturadas, os profissionais em sua grande maioria tiveram dificuldade de entender a inserção do NASF-AB na APS. Com entendimento de que funcionaria como "mini ambulatório". Percebeu-se muita carência de conhecimento, no entanto, foram notados avanços no decorrer do desenvolvimento das rodas de conversas, tendo em vista um dispositivo direcionado a pessoas e às necessidades e aos problemas tendo como pano de fundo o território e os contextos ${ }^{22}$. 


\section{Quadro 5 - Cordéis da quinta roda de conversa}

\section{AS PIS por Silvana Souza}

A Política Nacional de Práticas Integrativas preconiza a assistência integral do indivíduo.

Cada região de saúde, elenca a prioridade, qual que é a da Ceilândia, só vocês sabem a verdade.

As PIS são tecnologias eficazes e seguras, tratam da integralidade de todas as criaturas.

Eu sou suspeita de falar, de um assunto que gosto tanto transformei minha alegria, agorinha nesse canto.
São tantas práticas, meu filho, que é difícil escolher, só fazendo, só sentindo, só sentindo, para ver.

A medicina tradicional, a chinesa e a indiana conquistaram minha vida, vou fazer toda semana.

A estratégia da família é um ótimo local, pra se aplicar as PIS, tirar o povo do hospital.

Cada pessoa é responsável por cuidar de sua saúde, vão se achegando minha gente,

vamo tomar de atitude.

Reiki, yoga, biodança, vão te ajudar na balança, não há limite de idade, vai do idoso à criança.

Peço a licença, minha gente, vou ficando por aqui, ocês tenham um bom trabalho, semana que vêm tem mais.

\section{O início do fim, o meio e o começo por Silvana Souza}

Essa família passou maus percalços. Apesar de tudo o importante foi fazê tantos laços.

Joaquim agora sabe como cuidar da criança. Depois da paineira lhe passar tanta confiança.

Agora paineira conta com outras instituições
Para fazer os Silva ter mais condições.

Zé Neto tá crescendo e filó envaidecendo. Tudo parece caminhar e já sabem quem o menino apadrinhar.

Teobaldo foi companheiro, amigo e profissional. Agora contamos com ele até para falar sobre o emocional.
Por isso vamos continuar acompanhando. Nossa história ainda tem muito o que acontecer.

A família dos Silva e paineira jamais irão esmorecer...

\section{Muito Agradecidas por Silvana Souza e Daniela Oliveira}

Cês receberam uma visita, muito dá importante.

Silvana, Daniela e também a Rafaela.

Nós não viemos aqui pra passar conhecimento.

O tempo que nós passamos foi muito aproveitamento.

Nós cantamos a história de Joaquim e Filó. E também
Dona Fulô, a bichinha da avó.

A estratégia da família será uma realidade. Bem aqui nessa unidade.

Onde ocês trabalha bem juntim.

Muitas coisas relembramos, humanização, atitude... não precisam se preocupar de sobrar.

Ocês têm muita virtude!

Outras coisas abrodamos. NASF, PTS, PST... E de outra ressaltamos.

Nós lembramos de ocês. Nessas estradas dessa vida, esperamos nos encontrar, dos 
Fonte: elaborado pelas autoras.

Ao contrário dos outros estados que seguem a Política Nacional de Práticas Integrativas e Complementares em Saúde (PNPICS), o DF tem a sua própria Política de Práticas Integrativas (PIS), que, diferente da nacional do Ministério da Saúde (MS), não reconhece o termo complementar. As práticas integrativas de saúde no DF têm uma abordagem focada na multidimensionalidade física, mental, psíquica, afetiva e espiritual, sendo tecnologias de autocuidado e fortalecimento de vínculo terapêutico que integra a pessoa, o ambiente e a sociedade ${ }^{24}$.

A último roda de conversa, para além de um espaço de produção de conhecimento, também foi uma oportunidade de ressignificar, seja nas relações entre os profissionais quanto com gestores, com intuito de dar importância aos momentos de confraternização, acolhimento, espaço de fala e encorajar relações interpessoais com "aproximações da subjetividade: afeto, empatia e alteridade", a fim de obter relações mais humanizadas e garantir relações mais saudáveis. Nessa ocasião em especial, foi notado além do afeto a promoção da empatia profissional, pois "demanda o desenvolvimento de autoconhecimento e capacidade de identificar as manifestações verbais e não verbais, explícitas ou contraditórias, o resultaria na modulação social e cultural dessas manifestações"25.

Trabalhar no modelo de ESF exige dos profissionais mudanças tecnoassistenciais, para o desmonte do paradigma do modelo biomédico. A visão da promoção da saúde insere-se como alternativa às ações e serviços centrados na doença ou na figura do médico. Como objetivo a ser alcançado, a ampliação do escopo de atenção implica numa relação estreitada entre gestores, profissionais e usuários. Para Netto $(2018)^{26}$ “o debate sobre a mudança na formação dos profissionais de saúde justifica-se pela necessidade de romper os 
limites impostos pelo racionalismo técnico e pela fragmentação do conhecimento, condicionados hegemonicamente pelo paradigma cartesiano". E que as formações educativas e participativas têm poder de adequar e construir novas tecnologias e metodologias de trabalho direcionadas à realidade dos serviços e do território, visto que possibilitam a formação de profissionais críticos e reflexivos, por meio do "fazer fazendo reflexivamente". As formações educativas devem possibilitar a relação da teoria com prática, tracejados pelo processo de "reflexão-na-ação",26, como uns do produto da roda de conversa escrito em conjunto com participantes, uma paródia da cantora Renata Rosa: "Me leva" (ver Quadro 6). Verifica-se que a construção coletiva é essencial no processo educativo de qualquer pessoa.

\section{Quadro 6: paródia da música "Me leva" da cantora Renata Rosa}

\begin{tabular}{|c|c|c|}
\hline $\begin{array}{l}\text { A estratégia da família } \\
\text { envolveu você, }(2 \mathrm{x})\end{array}$ & $\begin{array}{l}\text { Me leva, } \\
\text { Me levaa }\end{array}$ & $\begin{array}{l}\text { Aa semente foi plantada, } \\
\text { ESF floresceu, }\end{array}$ \\
\hline Me leva, & & Me leva, \\
\hline Me leva, & Uma gestão compartilhada, & Me leva, \\
\hline Me levaa & $\begin{array}{l}\text { nós vamos buscar, } \\
\text { Me leva, }\end{array}$ & Me levaa \\
\hline Um PTS estruturado e um & Me leva, & Aqui terminam nossas \\
\hline PST, $(2 \mathrm{x})$ & Me levaa & oficinas, \\
\hline Me leva, & & Me leva, \\
\hline Me leva, & Reunião de equipe nós & Me leva, \\
\hline Me levaa & $\begin{array}{l}\text { vamos fazer, } \\
\text { Me leva, }\end{array}$ & Me levaa \\
\hline $\begin{array}{l}\text { Considerar o usuário um ser } \\
\text { integral }\end{array}$ & Me leva, & \\
\hline $\begin{array}{l}\text { integral, } \\
\text { Me leva, }\end{array}$ & Me levaa & \\
\hline
\end{tabular}

Elaborado pelas autoras.

Essas ações reflexivas que também são denominadas de "trabalho vivo" têm como estrutura basilar a reestruturação produtiva em saúde. Combinam com a ideia de “problematização dos modos de se produzir saúde como um plano político-metodológico de análise micropolítica do trabalho vivo em ato" e pense a saúde na APS como terreno de tensionamentos e desafios os quais estão em constantes mudanças e reinvenção, implicados 
pela imprevisibilidade, mas que se tornam uma oportunidade de espaço aberto para o aparecimento de potências entre os atores envolvidos ${ }^{27}$.

\section{CONSIDERAÇÕES FINAIS}

Os participantes relataram que a estratégia de utilização da literatura de cordel como material educativo foi um momento ímpar dentre as abordagens vivenciadas no processo de conversão das equipes da APS em Ceilândia-DF. Com as rodas de conversa foi possível perceber amadurecimento quanto à concepção da ESF e diminuição de barreiras existentes nas relações interpessoais dos participantes. Esse recurso possibilitou uma relação dialética traduzida pelas elucidações das experiências, o que facilitou as discussões reflexivas, como também reconhecimento da figura do profissional frente à conversão do modelo de atenção à saúde.

Houve despertamento e alinhamento dos profissionais quanto aos interesses de implementação de ESF como um modelo proprietário da APS. Reconhece-se que as capacitações não devem ser pontuais e isoladas, mas contínuas e com participações integrativas de todos atores envolvidos, desde a concepção até a execução. A tutoria foi a metodologia que mais se aproximou das experimentações positivas de ações educativas pelos participantes. Todas as experiências devem ser consideradas e não descartadas, por mais que sejam equivocadas, ou seja, é necessário "abaixar a guarda" e postar-se com ética

profissional e respeito à visão de mundo de cada um. É notório a busca pela validação e valorização quanto dos processos de trabalho anterior à implantação da ESF, o modelo biomédico, no sentido de não desconsiderar todas as ações, mas que se constituem ao longo do tempo, se adaptando de forma gradual a inserção de metodologias, arranjos e tecnologias mais comunitária e contextualizadas a realidade imposta. 
Trabalhar os conteúdos dentro da tipologia de rimas ressignificou todo o processo de instalação da ESF, tanto para os participantes quanto para os facilitadores deste estudo. Além de promover aprendizado, o contexto literário permitiu o aparecimento da transculturalidade que legitima a educação popular como práticas de saúde. Outro fator importante que possibilitou implicação mútua entre os presentes na realização da roda de conversa foi a introdução de instrumentos músicas e danças durante o canto dos cordéis.

Portanto, a literatura de cordel nas rodas de conversas permitiu a circularidade do conhecimento, trocas de saberes, um ambiente sem cobranças e principalmente um espaço para brincadeiras, entendendo que o ato de brincar é uma forma de comunicação, no qual se tenta imitar realidade com a possibilidade de fazer e (re)fazer os processos. Os cordéis tornaram-se a ponte necessária entre os inúmeros obstáculos da conversão do modelo de saúde com equipes de Ceilândia-DF.

\section{REFERÊNCIAS BIBLIOGRÁFICAS}

1. PAIM, Jairnilson Silva 2009.Uma análise sobre o processo da Reforma Sanitária brasileira. Saúde em Debate, Rio de Janeiro, v. 33, n. 81, p. 27-37, jan./abr. 2009.

2. MOROSINI, Márcia Valéria Guimarães Cardoso; FONSECA, Angélica Ferreira; LIMA, Luciana Dias de. Política Nacional de Atenção Básica 2017: retrocessos e riscos para o Sistema Único de Saúde. Saúde debate, Rio de Janeiro, v. 42, n. 116, p. 11-24, jan. 2018.

3. STARFIELD, B. Primary Care: concept, evaluation and policy. New York: Oxford University Press, 1992.

4. Starfield B. Atenção primária: equilíbrio entre necessidades de saúde, serviços e tecnologia. Brasil. Ministério da Saúde, 2002.

5. MELO, Eduardo Alves; MENDONCA, Maria Helena Magalhães de; TEIXEIRA, Márcia. A crise econômica e a atenção primária à saúde no SUS da cidade do Rio de Janeiro, Brasil. Ciênc. saúde coletiva, Rio de Janeiro, v. 24, n. 12, p. 4593-4598, Dec. 2019.

6. AGÊNCIA BRASIL. EBC.editorial. publicado 13/11/2018. [acessado 2020 Julh 2]. Disponível em:https://agenciabrasil.ebc.com.br/saude/noticia/2018-11/brasil-gasta-r-348-pordia-com-saude-de-cada-habitante-diz-cfm.

7. Brasil. Ministério da Saúde. Secretaria de Atenção em Saúde. Departamento de Atenção Básica. Manual do instrumento de avaliação da atenção primária à saúde: primary care 
assessment tool pcatool - Brasil / Ministério da Saúde, Secretaria de Atenção em Saúde, Departamento de Atenção Básica. - Brasília: Ministério da Saúde, 2010.

8. Mendes, Eugênio Vilaça $\mathrm{O}$ cuidado das condições crônicas na atenção primária à saúde: o imperativo da consolidação da estratégia da saúde da família. / Eugênio Vilaça Mendes. Brasília: Organização Pan-Americana da Saúde, 2012. 512 p.: il.

9. Macinko J. Atenção Primaria à Saúde: estratégia chave para a sustentabilidade do SUS. Seminário Atenção Primária à Saúde, OPAS, Brasília, abril, 2018. Brasil. [acessado 2020 Jun 16]. Disponível em: https://apsredes.org/wp-content/uploads/2018/04/Mesa-1James-Macinko.pdf

10. Portal inovação na inovação da gestão DO SUS. [acessado 2020 Jun 14]. Disponível em https://apsredes.org/organizacao-da-atencao-primaria-saude-no-distrito-federal/.

11. CORREA, Daniel Seabra Resende Castro et al. Movimentos de reforma do sistema de saúde do Distrito Federal: a conversão do modelo assistencial da Atenção Primária à Saúde. Ciênc. saúde coletiva, Rio de Janeiro, v. 24, n. 6, p. 2031-2041, June 2019.

12. CAMPOS, Gastão Wagner de Souza. Um método para análise e cogestão de coletivos: a constituição do sujeito, a produção de valor de uso e a democracia em Instituições: o método da roda. São Paulo: Hucitec, 2000.

13. Pagliuca, Lorita Marlena Freitag, Oliveira, Paula Marciana Pinheiro, Rebouças, Cristiana Brasil de Almeida, \& Galvão, Marli Teresinha Gimeniz. (2007). Literatura de cordel: veículo de comunicação e educação em saúde. Texto \& Contexto - Enfermagem, 16(4), 662-670.

14. OLIVEIRA, Paula Marciana Pinheiro de et al. Literatura de cordel como estratégia educativa para prevenção da dengue. Texto \& Contexto - Enfermagem, v. 20, n. 4, p.766$773,2011$.

15. SILVA, Verônica Diniz. A literatura de cordel e suas contribuições para o ensino desse gênero na sala de aula. Portal de periódicos eletrônico da UFAC. 2016.

16. GALHEIGO, Sandra Maria. Terapia ocupacional, cotidiano e a tessitura da vida: aportes teórico-conceituais para a construção de perspectivas críticas e emancipatórias. Cad. Bras. Ter. Ocup., São Carlos, v. 28, n. 1, p. 5-25, mar. 2020.

17. OLIVEIRA, Sidinei Rocha de; PICCININI, Valmiria Carolina. Validade e reflexividade na pesquisa qualitativa. Cad. EBAPE.BR, Rio de Janeiro, v. 7, n. 1, p. 88-98, Mar. 2009.

18. PONTE, Hermínia Maria Sousa da; OLIVEIRA, Lucia Conde de; AVILA, Maria Marlene Marques. Desafios da operacionalização do Método da Roda: experiência em Sobral (CE). Saúde debate, Rio de Janeiro, v. 40, n. 108, p. 34-47, Mar. 2016.

19. Silva, Nair Chase da Atenção primária em saúde e contexto familiar: análise do atributo 'centralidade na família' no PSF de Manaus. / Nair Chase da Silva. Rio de Janeiro: s.n., 2010 . 
20. PAVONI, Daniela Soccoloski; MEDEIROS, Cássia Regina Gotler. Processos de trabalho na equipe Estratégia de Saúde da Família. Rev. bras. enferm., Brasília, v. 62, n. 2, p. 265271, Apr. 2009.

21. FERREIRA, Lorena et al. Educação Permanente em Saúde na atenção primária: uma revisão integrativa da literatura. Saúde debate, Rio de Janeiro, v. 43, n. 120, p. 223-239, Mar. 2019.

22. SOUZA, Thiago Santos; MEDINA, Maria Guadalupe. Nasf: fragmentação ou integração do trabalho em saúde na APS? Saúde debate, Rio de Janeiro, v. 42, n. spe2, p. 145-158, Oct. 2018.

23. ARAUJO, M.B.S.; ROCHA, P.M. Trabalho em equipe: um desafio para a consolidação da estratégia de saúde da família. Ciência e saúde coletiva v.12 n.2. Rio de janeiro, mar-abr. 2007.

24. Portal GDF- Práticas Integrativas de Saúde [acessado 2020 Jun 05]. Disponível em: http://www.saude.df.gov.br/praticas-integrativas-de-saude/ .

25. SCHOLZE, Alessandro da Silva; DUARTE JUNIOR, Carlos Francisco; SILVA, Yolanda Flores e. Trabalho em saúde e a implantação do acolhimento na atenção primária à saúde: afeto, empatia ou alteridade? Interface (Botucatu), Botucatu, v. 13, n. 31, p. 303-314, Dec. 2009.

26. NETTO, Luciana; SILVA, Kênia Lara. Prática reflexiva e o desenvolvimento de competências para a promoção da saúde na formação do enfermeiro. Rev. esc. enferm. USP, São Paulo, v. 52, e03383, 2018.

27. NEVES, Claudia Abbês Baêta. Saúde: a cartografia do trabalho vivo. Cad. Saúde Pública, Rio de Janeiro, v. 24, n. 8, p. 1953-1955, Aug. 2008. 